\title{
Reviscometer Evaluation of the Skin Condition after Applying Retinol and Vitamin C Complex in Menopausal Women
}

\author{
Aneta Wójcik' ${ }^{1}$ Ewelina Bartnicka ${ }^{2}$, Helena Rotsztejn ${ }^{1}$ \\ ${ }^{1}$ Department of Cosmetology and Aesthetic Dermatology, Faculty of Pharmacy, Medical University of Lodz, \\ Lodz, Poland \\ ${ }^{2}$ Department of Cosmetic Raw Materials Chemistry, Faculty of Pharmacy, Medical University of Lodz, \\ Lodz, Poland \\ Email: salon@image-kozienice.pl, ewelina.bartnicka@umed.lodz.pl, helena.rotsztejn@umed.lodz.pl
}

Received 16 June 2016; accepted 13 August 2016; published 16 August 2016

Copyright @ 2016 by authors and Scientific Research Publishing Inc.

This work is licensed under the Creative Commons Attribution International License (CC BY).

http://creativecommons.org/licenses/by/4.0/

(c) (i)

\section{Abstract}

Background: Topical application of retinol connected with the improvement of various parameters of aging skin is often used in post- and menopausal women. Vitamin A - vitamin C complex treatments may influence skin surface lipids and boost the fibroblasts activity as well as increase their number, thus inducing the improvement of its elasticity. Objective: In the current paper, we demonstrate and evaluate the impact of retinol and vitamin C complex on the face and neck skin elasticity level in a group of women aged 50 - 69. Method: Reviscometer RVM 600 (Courage \& Khazaka, Germany) was used to measure forehead, cheeks and neck skin elasticity in a group of 21 women. Each of the patients was subjected to four treatment sessions that included skin elasticity measurements before each of the three retinol peels at 3-week intervals and one 3-week after the completion of the therapy. Results: Significant increase in the cheeks and neck skin elasticity was observed in the study group. Conclusion: Treatments including retinol with vitamin $\mathrm{C}$ - vitamin A complex significantly influence the improvement of skin elasticity, thus reducing the signs of skin aging.

\section{Keywords}

Retinol, Vitamin C - Vitamin A Complex, Reviscometer

\section{Introduction}

Skin aging is a process influenced by numerous genetical, hormonal and environmental factors. With time pass-

How to cite this paper: Wójcik, A., Bartnicka, E. and Rotsztejn, H. (2016) Reviscometer Evaluation of the Skin Condition after Applying Retinol and Vitamin C Complex in Menopausal Women. Journal of Cosmetics, Dermatological Sciences and Applications, 6, 148-155. http://dx.doi.org/10.4236/icdsa.2016.64019 
ing, different processes occur in skin tissue leading to its remodeling. Wrinkles, hyperpigmentation and dryness become noticeable. Moreover, as elastine fibres deteriorate, a visible loss of elasticity is observed being the main reason for connective tissue aging [1] [2].

Firmness and elasticity increase is the most important step to fight against skin aging symptoms. Therefore, substances which could cause the least possible side effects at the highest clinical effectivity are continually being searched for. One of those is retinoid. However, their topical application can result in adverse effects [3] [4]. Retinol (ROL), as one of the retinoids decreases the aging signs with little irritation, thus it is more and more often used in rejuvenating cosmetics and treatments. Its anti-aging action involves delaying and inhibiting the matrix degradation by blocking the enzymes which decompose collagen and preventing oxidation stress. Retinol reduces wrinkles and improves elasticity of the skin because it stimulates collagen and glycosaminoglycans (GAG) synthesis by increasing TGF- $\beta$ (Transforming Growth Factor) activity and synthesis of procollagen [4]-[9].

Vitamin $\mathrm{C}$ is a cofactor of proline and lysine hydroxylase, which are the enzymes responsible for the stability and collagen fibers crossing [10]. Furthermore, it activates the transcription of $m$ RNA procollagen, thereby stimulating the synthesis of collagen I and III of the skin [11]. Additionally, vitamin C also acts as an antioxidant by scavenging and quenching free radicals and by regenerating vitamin $\mathrm{E}$ [12].

The aim of the study was to evaluate the effect of vitamin A and vitamin C complex on improvement of skin elasticity in the group of menopausal women before and after the application of 3 treatments for the face and neck, at intervals of 21 days.

\section{Methods}

\subsection{Patient Population}

The study was conducted in 21 postmenopausal women not using hormone replacement therapy. Age of the patients ranged from 50 - 69 years (mean age $59.1 \pm 4.6$ ) (Table 1). All subjects were informed of the application method and transient side effects related to the specific treatment. Patients received detailed guidance on skin care at home, including the use of high photoprotection - min. 50 SPF and regenerating cosmetics. The subjects did not change their skin care products during the study and did not use antibiotics and retinoids (neither topically nor generally) for six months before the beginning of the treatment.

\subsection{Procedure}

Using Reviscometer RVM 600 (Courage \& Khazaka electronic GmbH, Cologne, Germany), skin elasticity measurements were performed on the face - forehead, both cheeks, and right and left side of the neck. For the measurement of skin elasticity the positioning head of the device was used. It was pressed against the selected areas of the skin with a force of $1 \mathrm{~N}$ on $0-1000 \mu \mathrm{s}$ (according to the manufacturer's instructions). The head, attached to the skin with bilateral rings, allows the user to any number of measurements at a selected angle relative to the skin, eg. $10^{\circ}, 20^{\circ}$ or $45^{\circ}$. The probe head contains two sensors which are placed on the skin. One of them transmits acoustic waves and the other one receives them. The principle of operation is based on measuring the time course of a single acoustic wave resonance-RRT (Resonance Running Time), with an energy of $1.77 \mu \mathrm{J}$ in time $0-1000 \mathrm{~ms}$ (according to the manufacturer's instructions). The wave penetrates the skin in a manner dependent on the humidity and elasticity. Time of the wave's transition from the transmitter to the sensor is a measurable parameter. The longer the time required for penetration of the skin by the wave, the greater the measured value and the lower elasticity [13] [14].

In the present study, the participation of the patient consisted of three treatments performed every 3 weeks and a check-up visit 3 weeks after completing the study. During the visits, four sets of skin elasticity measurements were conducted, at $0 / 180^{\circ}, 45 / 225^{\circ}, 90 / 270^{\circ}, 135 / 315^{\circ}$ relative to the skin. The first set of measurements of the outer skin tension at baseline (before the first topical use of the complex) on the skin of the face (forehead,

Table 1. Patients' age.

\begin{tabular}{ccccccc}
\hline Type of the peel & N & Minimum & Maximum & Median & Average & Standard deviation SD \\
\hline Vitamin C - vitamin A complex & 21 & 50 & 69 & 58 & 59.1 & \pm 4.6 \\
\hline
\end{tabular}

$\mathrm{N}=$ number of subjects. 
right and left cheek), and the right and left side of the neck. The second and the third set of measurements of the above-mentioned parts were taken, respectively, after 3 and 6 weeks immediately prior to the application of peeling. The fourth set of measurements was performed in the 9th week as a control measure after the treatment.

Measurement data were analyzed by a computer program and collected in a database. The results were averaged to standard ambient conditions - temperature of $23.3^{\circ} \mathrm{C} \pm 1.5^{\circ} \mathrm{C}$ and a relative humidity of $46.9 \% \pm 10.5 \%$.

Prior to each treatment session, the face and neck were cleansed with water and a mild soap, dried and left without cream. Then, after five hours the level of the skin elasticity was measured on the forehead, both cheeks and on the right and left side of the neck. After conducting measurements on the face and neck, commercial peel was applied (Retix C: $8 \%$ vitamin C, $2 \%$ retinol). First $8 \%$ vitamin $\mathrm{C}$ was gently massaged until absorbed, and then a $2 \%$ retinol mask was applied for $4-6$ hours. Patients were sent home with the recommendation to rinse out the excess of the cosmetics using pure water at the indicated time and to apply a moisturizer $2-3$ times a day, with a contraindication for sunbathing and the use of high photoprotection. None of the home care products contained vitamin $\mathrm{C}$ and/or retinoids.

\subsection{Statistical Analysis}

Statistical examination of the experimental data was performed in STATISTICA (Statistica 6.0 StatSoft, Inc., Tulsa, OK, USA). RRT values were reported in four directions $0 / 180^{\circ}, 45 / 225^{\circ} 90 / 270^{\circ}, 135 / 315^{\circ}$. The measurement data were divided according to the point of measuring (forehead, left and right cheek, left and right sides of the neck) and the time of measurement (0,3,6 and 9 weeks after the beginning of the treatment). Four sets of measurements were carried out at a predetermined position of the probe. To evaluate the overall skin firmness, average value for the acoustic wave flow direction was used. The assessment of the impact of the peel on the elasticity of the skin was checked with Wilcoxon test for dependent samples in successive periods of time, treating the first measurement as a blank. The graphs indicate mean values and statistical significance level relative to the baseline examination * $-\mathrm{p}<0.05 * *-\mathrm{p}<0.01 * * * \ldots \mathrm{p}<0.001$.

\section{Results}

The first study area of the face was the forehead. On the basis of RRT measurements, it was concluded that there was no change between the baseline measurement and the final. The changes percentage between the mean values of the first and the last measurement ranged between $0.4 \%$ and turned out to be statistically insignificant (Figure 1). The research shows that 3 retinol treatments had no effect on improving the elasticity of the skin on the forehead.

For the right cheek, the average measurement value was $189.6 \pm 93.0 \mu \mathrm{J} / \mu \mathrm{s}$. The treatments performed allowed

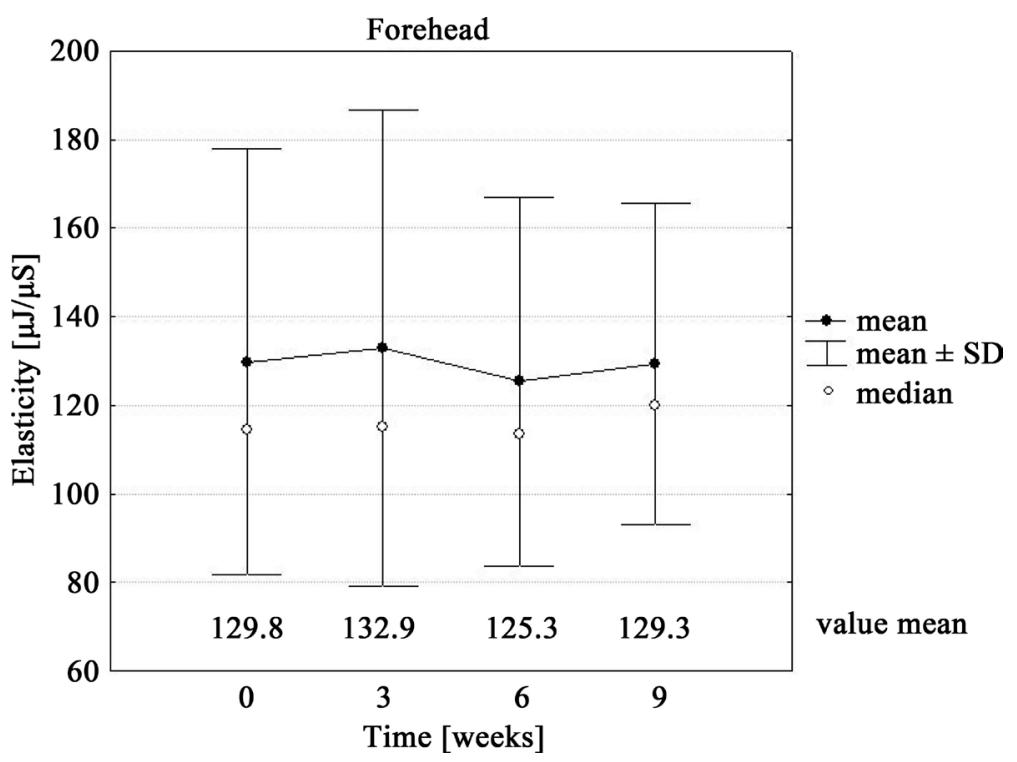

Figure 1. Average elasticity values of skin on the forehead $(p>0.05 \mathrm{~ns})$ at a time interval for vitamin C - vitamin A complex. 
to observe statistically significant differences $p<0.100$, reducing the average value by $13.1 \%$ to the level of $164.8 \pm 59.7 \mu \mathrm{J} / \mu$ s (Figure 2).

However, the average baseline value of the left cheek was $170.8 \pm$ page $85.5 \mu \mathrm{J} / \mu$ s and decreased to a value of $152.8 \pm 61.5 \mu \mathrm{J} / \mu \mathrm{s}$, which represented $10.5 \%$ of the result with respect to the average baseline value and was at a significance level of $p<0.02$ (Figure 2). Similarly to the right cheek, the left cheek skin elasticity increase was observed after the third treatment.

Statistically significant changes $\mathrm{p}<0.005$ were also obtained for both cheeks - the U zone, where improvement in skin elasticity was observed in the ninth week of the study, three weeks after completion of the treatments. There was an elasticity increase of $11.9 \%$ (the average value of the measurement baseline was $180.2 \pm$ $89.6 \mu \mathrm{J} / \mu \mathrm{s}$ and decreased to $158.8 \pm 60.7$ final $\mu \mathrm{J} / \mu \mathrm{s}$ ) (Figure 2).

The series of 3 treatments also resulted in an improvement of skin elasticity for the right and left side of the neck. After 9 weeks since the first treatment, the right side of the neck showed an improvement of $9.3 \%$ (from an average of $303.6 \pm 146.8$ initial $\mu \mathrm{J} / \mu \mathrm{s}$ to the value of $275.5 \pm 123.3 \mu \mathrm{J} / \mu \mathrm{s})$ for the significance level of $\mathrm{p}<$ 0.05 (Figure 3).

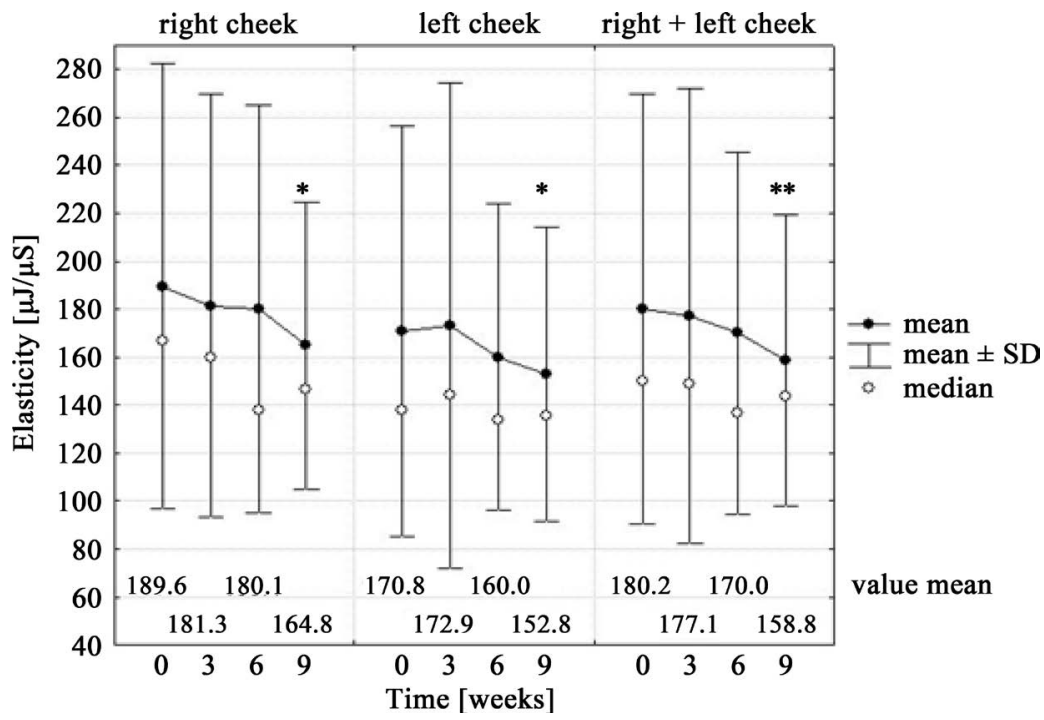

Figure 2. Average elasticity values of skin on the left and right cheek, and the $U$ area at time intervals for vitamin $\mathrm{C}$ - vitamin A complex.

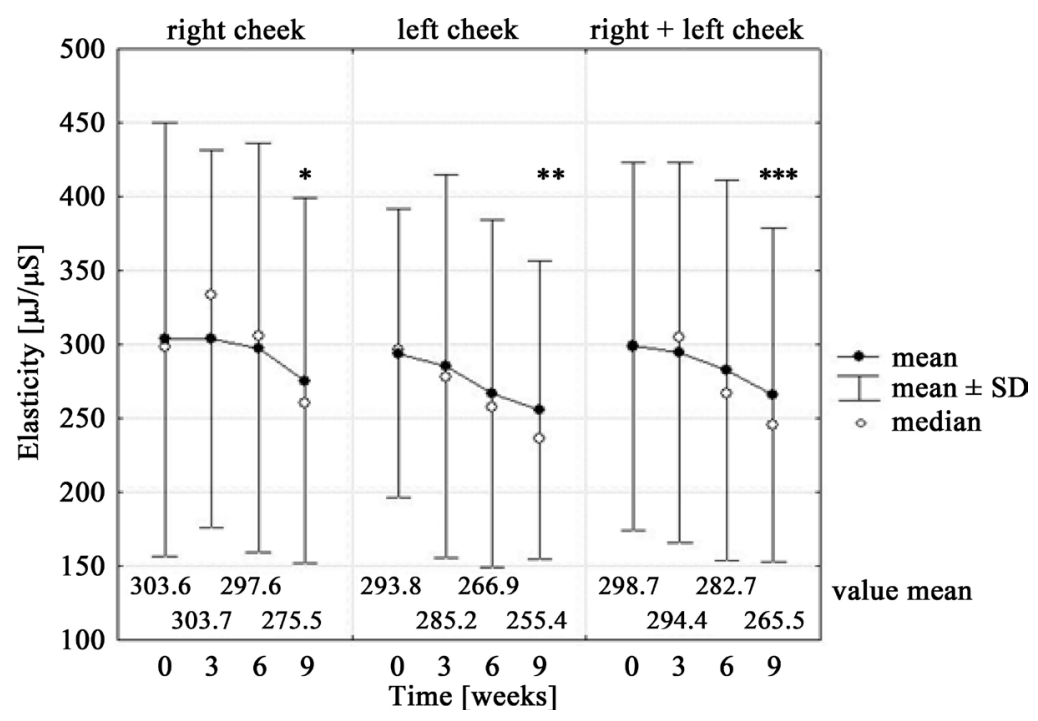

Figure 3. Mean values of the resonance time on the neck at time interval for vitamin C - vitamin A complex. 
As for the left side of the neck, the mean value before treatments was $293.8 \pm 97.6 \mu \mathrm{J} / \mu \mathrm{s}$. Three treatments improved skin elasticity by $13.1 \%$ (to $255.4 \pm 101.1$ value $\mu \mathrm{J} / \mu \mathrm{s}$ ). Based on the results and tests of significance, statistically significant differences were obtained $\mathrm{p}<0.05$ (Figure 3 ).

Statistically significant changes $p<0.001$ were also obtained for both sides of the neck, where the improvement of the elasticity of the areas studied was observed in the ninth week of the study, three weeks after completion of therapy. Increased elasticity by $11.1 \%$ was observed, where the average baseline measurement value was $298.7 \pm 124.4 \mu \mathrm{J} / \mu \mathrm{s}$ and decreased to $265.5 \pm 112.9$ final $\mu \mathrm{J} / \mu \mathrm{s}$ (Figure 3 ).

\section{Discussion}

Applications of retinol and ascorbic acid complex to the skin surface can result in the improvement of various parameters of aging skin in post-and menopausal women such as an increase in the amount of the skin surface lipids and an increase in elasticity of the skin.

The paper shows the effects of applying retinol and vitamin C complex on the skin of the menopausal women as their skin shows visible signs of elasticity loss. Retinol contributes to the increase in the activity of fibroblasts and collagen synthesis, and reduces the level of metalloproteinases (MMPs) [5]. Furthermore, topical application of retinol increases the expression of procollagen protein type-1, tropoelastin proteins and fibrillin- 1 and increases the concentration of glycosaminoglycan in chronologically aging skin, thus contributing to smoothing fine lines [6] [7].

Retinol molecule (Figure 4) is formed of cyclohexenyl ring connected to a long-chain isoprenoid (contains four conjugated bindings), called "tail" and a very important final group-polarhydroxyl group, which determines the chemical properties and biological functions of this compound in the human body. The particle size of retinol is $995,89 \AA^{3}$ [Hyperchem8.0.8]. It has a high lipophilic properties, which is confirmed by the $\log p=4.62$ [Hyperchem8.0.8]. Molecule of the ratio of lipophilicity penetrates the stratum corneum of the skin well penetration [15].

Retinol in human skin is quickly converted into its active form - retinoic acid, with which strong expression of CRBP- $m$ RNA protein binding that retinoid follows. In addition, the use of retinol promotes exfoliation, whereby it initiates inflammatory reactions in the skin. According to this hypothesis stimulated keratinocytes have the ability to release IL-1 [16], IL-6, IL-8 [17] cytokines. A process of connective tissue remodeling occurs by modulating the degradation of the intercellular matrix dependent on IL-1, which induces the release of interleukin 6. As a result, fibroblast activity, the production of glycosaminoglycans and neoangiogenesis increase [18]. In histological evaluation, it results in widening of Grenz zone, situated directly below the epidermis, and within the epidermis an increase in keratinocyte proliferation as well as thickening of the viable layers while thinning the stratum corneum [19].

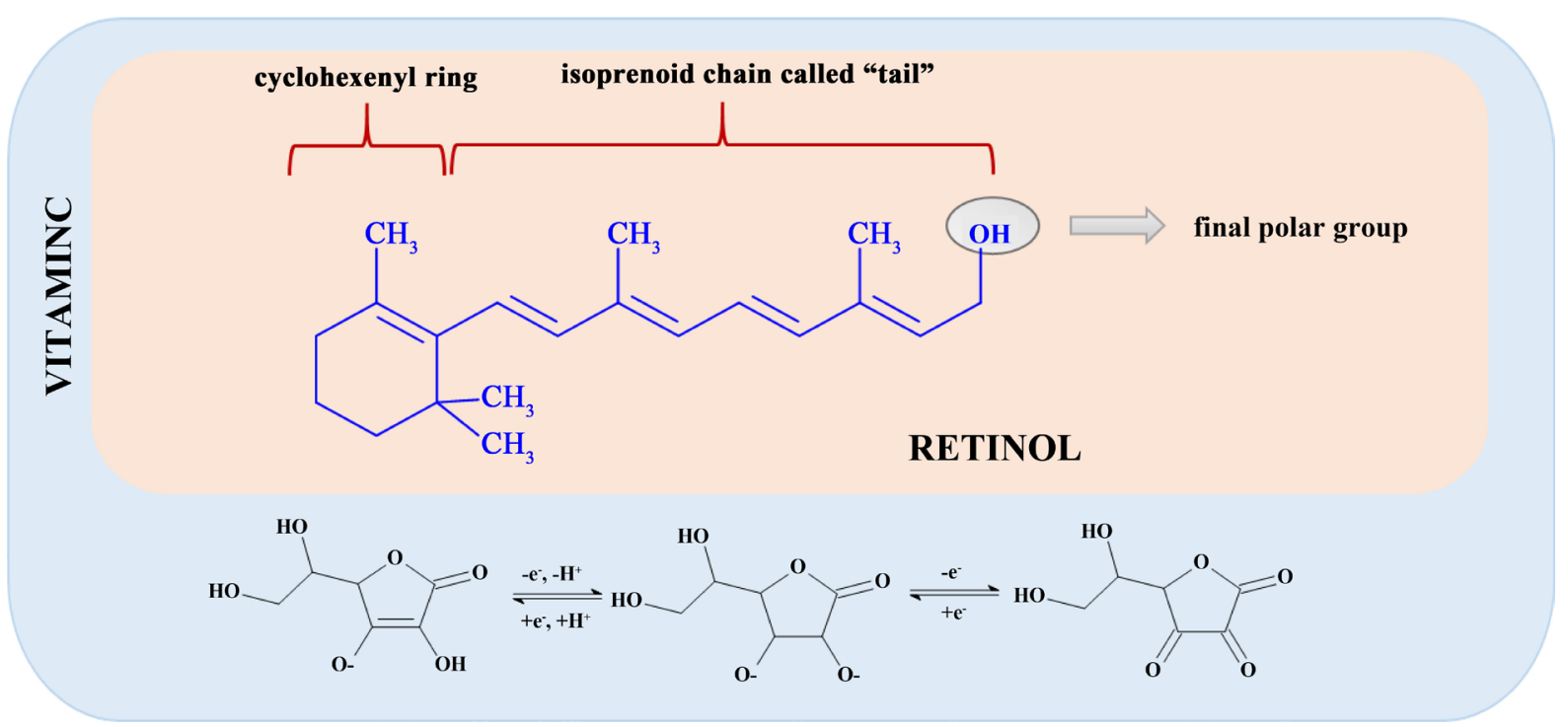

Figure 4. The chemical structures of retinol and influence of the vitamin $\mathrm{C}$ on the skin. 
For the purpose of the study we arbitrarily decided on using retinol in complex with vitamin $\mathrm{C}$ to maximize the expected results. $L$-ascorbic acid enhances the $m$ RNA level of collagens I and III [20]. Moreover, using the pure form of vitamin $\mathrm{C}$ - ascorbic acid in the serum, phase of the studied formulation was to prevent the transformation of the basic retinoid form - retinol. In addition, serum with vitamin $\mathrm{C}$ enriches the peel properties through mitigating any irritation resulting from the use of retinol and blocks lipid peroxidation in cell membranes, by deactivating reactive oxygen species (ROS) (Figure 4) [21] [22].

Our study confirmed that topical application of a formulation containing both retinol and vitamin $\mathrm{C}$ can reverse at least partially, lesions induced both by chronological aging and photoaging. In two parallel studies lasting 3 and 6 months respectively combination of $0.07 \%$ and $3.5 \%$ retinol, vitamin $\mathrm{C}$ and $0.04 \%$ retinol, and $3 \%$ vitamin $\mathrm{C}$ was used. After 3 months of treatment researchers observed thinning of the stratum corneum while thickening live layers of the epidermis and an increase in the number and ordering of the keratinocytes. After 6 months of treatment histological changes the dermis were observed. There was a decrease in the type III procollagen in relation to the type I, while expanding of the Grenz zone [23].

The overall affects of the treatments were satisfying. After as few as 3 applications the skin was visibly more elastic and firm, the face wrinkles were less noticeable and the skin became less saggy.

The conducted study of retinol with vitamin A and vitamin C complex in a series of three treatments result in improving the elasticity of the skin of the face and neck at the level of $p<0.01$ for U-zone and $p<0.001$ for the neck, as shown in Figure 5.

\section{Conclusion}

The results of this study indicate a significant effect of vitamin C - vitamin A complex on reviscometer evaluation of the skin. The complex used in the study causes an increase in skin elasticity, particularly in the U-zone and the skin of the neck, which may be associated with a better penetration of the molecule in the areas with smaller surface lipids levels. Additionally, vitamin C can protect skin against ROS and influence antiaging processes. Treatments using vitamin $\mathrm{C}$ and vitamin A complex give us a hope to slow down the skin antiaging processes in menopausal women.

\section{Acknowledgements}

Financial supports from Medical University of Lodz, grants No 503/3-066-02/503-31-001 to E. B and No 503/3066-01/503-31-001 is gratefully acknowledged.

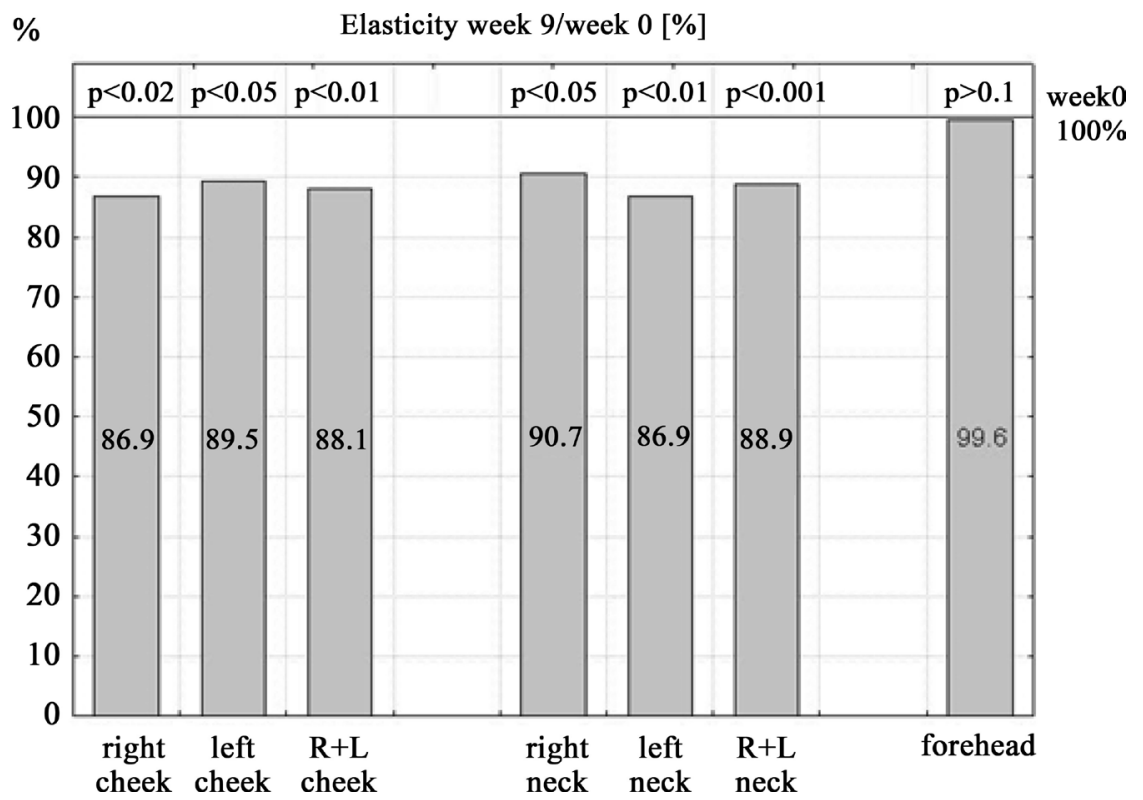

Figure 5. Comparison of the effectiveness of treatments after the application of vitamin $\mathrm{C}$ - vitamin A complex in time between the first and last visit (100\% is the first measurement). 


\section{Conflict of Interest}

The authors have no conflict of interests.

\section{References}

[1] Sherratt, M.J. (2009) Tissue Elasticity and the Ageing Elastic Fibre. Age, 31, 305-325. http://dx.doi.org/10.1007/s11357-009-9103-6

[2] Wójcik, A. and Rotsztejn, H. (2012) The Influence of Hormones on Skin Lipids in Women during Menopause. Rev Menopausal, 1, 41-44.

[3] Rona, C., Vailati, F. and Berardesca, E. (2004) The Cosmetic Treatment of Wrinkles. Journal of Cosmetic Dermatology, 3, 26-34. http://dx.doi.org/10.1111/j.1473-2130.2004.00054.x

[4] Sorg, O., Antille, C., Kaya, G. and Saurat, J.H. (2006) Retinoids in Cosmeceuticals. Dermatologic Therapy, 19, 289296. http://dx.doi.org/10.1111/j.1529-8019.2006.00086.x

[5] Varani, J., Warner, R.L., Gharaee-Kermani, M., et al. (2000) Vitamin A Antagonizes Decreased Cell Growth and Elevated Collagen-Degrading Matrix Metalloproteinases and Stimulates Collagen Accumulation in Naturally Aged Human Skin. Journal of Investigative Dermatology, 114, 480-486. http://dx.doi.org/10.1046/j.1523-1747.2000.00902.x

[6] Kafi, R., Kwak, H.S., Schumacher, W.E., et al. (2007) Improvement of Naturally Ages Skin with Vitamin A (Retinol). Archives of Dermatology, 143, 606-612. http://dx.doi.org/10.1001/archderm.143.5.606

[7] Rossetti, D., Kielmanowicz, M.G., Vigodman, S., Hu, Y.P., Chen, N., et al. (2011) A Novel Anti-Ageing Mechanism for Retinol: Induction of Dermal Elastin Synthesis and Elastin Fibre Formation. International Journal of Molecular Sciences, 33, 62-69. http://dx.doi.org/10.1111/j.1468-2494.2010.00588.x

[8] Sorg, O., Tran, C. and Saurat, J.H. (2001) Cutaneous Vitamins A and E in the Context of UV or Chemically Induced Oxidative Stress. Skin Pharmacology, 14, 363-372. http://dx.doi.org/10.1159/000056370

[9] Ligade, V.S., Sreedhar, D., Manthan, J. and Udupa, N. (2009) Cosmeceuticals: Are They Truly Worth the Cost? Indian Journal of Dermatology, Venereology and Leprology, 75, 8-9. http://dx.doi.org/10.4103/0378-6323.45213

[10] Hausman, E. (1967) Cofactor Requirements for the Enzymatic Hydroxylation of Lysine in a Polypeptide Precursor of Collagen. Biochimica et Biophysica Acta, 133, 591-593. http://dx.doi.org/10.1016/0005-2795(67)90566-1

[11] Caygill, J.C. (1969) Prevention of Tropocollagen Aggregation by L-Ascorbicacid. Biochimica et Biophysica Acta, 181, 334-336. http://dx.doi.org/10.1016/0005-2795(69)90260-8

[12] Lobo, V., Patil, A., Phatak, A. and Chandra, N. (2010) Free Radicals, Antioxidants and Functional Foods: Impact on Human Health. Pharmacognosy Reviews, 4, 118-126. http://dx.doi.org/10.4103/0973-7847.70902

[13] Paye, M., Mac-Mar, S., Elkhayat, A., Tarrit, C., Mermet, P. and Humbert, P.H. (2013) Use of the Reviscometer for Measuring Cosmetics-Induced Skin Surface Effects. Skin Research and Technology, 13, 343-349. http://dx.doi.org/10.1111/j.1600-0846.2007.00236.x

[14] Murakami, M., Tanno, O. and Kurokawa, H. (2009) Evaluation of Skin Mechanical Properties by Determining of Resonant Frequency and Loss Resistance with Tactile Sensor. Skin Research and Technology, 1, 125-126.

[15] Anderson, B.D. and Raykar, P.V. (1989) Solute Structure-Permeability Relationships in Human Stratum Corneum. Journal of Investigative Dermatology, 93, 280-286. http://dx.doi.org/10.1111/1523-1747.ep12277592

[16] Bell, T.V., Herley, C.B., Stetsko, D., et al. (1987) Expression of mRNA Homologous to Interleukin 1 in Human Epidermal Cells. Journal of Investigative Dermatology, 88, 375-379. http://dx.doi.org/10.1111/1523-1747.ep12469041

[17] Fisher, G.J., Wang, Z.Q., Datta, S.C., et al. (1997) Pathophysiology of Premature Skin Aging Induced by Ultraviolet Light. The New England Journal of Medicine, 337, 1419-1428. http://dx.doi.org/10.1056/NEJM199711133372003

[18] Kim, S.J. and Won, Y.H. (1998) The Effect of Glicolic Acid on Cultured Human Skin Fibroblasts: Cell Proliferative Effect and Increased Collage Syntehesis. The Journal of Dermatology, 25, 85-89.

[19] Okano, Y., Abe, Y., Masaki, H., Santhanam, U., Ichihashi, M., Fanasaka, Y., et al. (2003) Biological Effects of Glycolic Acid on Dermal Matrix Metabolism Mediated by Dermal Fibroblasts and Epidermal Keratinocytes. Experimental Dermatology, 12, 57-63. http://dx.doi.org/10.1034/j.1600-0625.12.s2.9.x

[20] Nusgens, B.V., Humbert, P. and Rougier, A. (2001) Topically Applied Vitamin C Enhances the mRNA Level of Collagens I and III, Their Processing Enzymes and TIMP1 in the Human Dermis. Journal of Investigative Derma- tology, 116, 853-859. http://dx.doi.org/10.1046/j.0022-202x.2001.01362.x

[21] Pinnell, S.R. (2003) Cutaneous Photodamage, Oxidative Stress, and Topical Antioxidant Protection. Journal of the American Academy of Dermatology, 48, 1-19. http://dx.doi.org/10.1067/mjd.2003.16

[22] Padayatty, S.J., Katz, A., Wang, Y., et al. (2003) Vitamin C as an Antioxidant: Evaluation of Its Role in Disease Pre- 
vention. Journal of the American College of Nutrition, 22, 18-35.

http://dx.doi.org/10.1080/07315724.2003.10719272

[23] Seité, S., Bredoux, C., Compan, D., et al. (2005) Histological Evaluation of a Topically Applied Retinol-Vitamin C Combination. Skin Pharmacology and Physiology, 18, 81-87. http://dx.doi.org/10.1159/000083708

Submit or recommend next manuscript to SCIRP and we will provide best service for you:

Accepting pre-submission inquiries through Email, Facebook, LinkedIn, Twitter, etc.

A wide selection of journals (inclusive of 9 subjects, more than 200 journals)

Providing 24-hour high-quality service

User-friendly online submission system

Fair and swift peer-review system

Efficient typesetting and proofreading procedure

Display of the result of downloads and visits, as well as the number of cited articles

Maximum dissemination of your research work

Submit your manuscript at: http://papersubmission.scirp.org/ 